\title{
Article \\ Influence of degradation products on the elastic stiffness properties of porous absorbable scaffolds made from bioabsorbable metals
}

\author{
Jannik Bühring 1,*(D), Maximilian Voshage 2, (D), Johannes Heinrich Schleifenbaum 2, (D), Holger Jahr ${ }^{3,(1)}$ and \\ Kai-Uwe Schröder 1, (iD) \\ 1 Institute of Structural Mechanics and Lightweight Design - RWTH Aachen University, 52062 Aachen, \\ Germany; office@sla.rwth-aachen.de \\ Institute of Anatomy and Cell Biology, University Hospital - RWTH Aachen University \\ Digital Additive Production - RWTH Aachen University, 52074 Aachen, Germany; \\ info@dap.rwth-aachen.de \\ * Correspondence: jannik.buehring@sla.rwth-aachen.de; Tel.:+49 241-80-96842
}

check for updates

Citation: Bühring, J.; Voshage, M.; Schleifenbaum, J.H.; Jahr, H.; Schröder, K.-U. Influence of degradation products on the elastic stiffness properties of porous scaffolds made from bioabsorbable metals. Preprints 2021, 1, 0 . https://doi.org/

Received:

Accepted:

Published:

Publisher's Note: MDPI stays neutral with regard to jurisdictional claims in published maps and institutional affiliations.

\begin{abstract}
For orthopaedic applications, additive manufactured (AM) porous scaffolds made of absorbable metals like magnesium, zinc or iron are of particular interest. They do not only offer the potential to design and fabricate bio-mimetic or rather bone equivalent mechanical properties, they also do not need to be removed in further surgery. Located in a physiological environment, scaffolds made of absorbable metals show a decreasing Young's modulus over time, due to product dissolution. For WE43 scaffolds, during the first days an increase of the smeared Young's modulus can be observed, which is mainly attributed to a forming substrate layer of degradation products on the struts surfaces. In this study the influence of degradation products on the stiffness properties of metallic scaffolds is investigated. For this, analytical calculations and finite element simulations are performed to study the influence of the substrate layer thickness and Young's modulus for single struts and for a new scaffold geometry with adapted polar $\mathrm{f} 2 \mathrm{cc}, \mathrm{z}$ unit cells. The finite element model is further validated by compression tests on AM scaffolds made from $\mathrm{Zn} 1 \mathrm{Mg}$. The results show, that even low thicknesses and Young's moduli of the substrate layer increases significantly the smeared Young's modulus under axial compression.
\end{abstract}

Keywords: additive manufacturing; scaffolds; bioabsorbable metals; biodegradation; lattice structures; stiffness properties

\section{Introduction}

The increasingly elderly population and the accompanying rising number of bone fractures lead to a significant rise in physical disabilities. The healing of larger bone defects is still a challenging task in orthopaedics. Using degradable implants eliminates the need for revision surgery, which may be required for some permanent medical devices. Thus, using such implants would not only benefit the patient, but also reduce healthcare costs [1]. Ideally, the implants should present a fully interconnected porous structure and should show equivalent mechanical properties, especially regarding the stiffness [2]. Such a biodegradable bone implant would allow fully natural bone regeneration, while the material gradually disappears in the body through absorption. These requirements can be fulfilled i.e. by additive manufactured (AM) lattice structures. Due to the large number of available materials and design parameters, almost any mechanical and material requirement profile can be set. Whereas biocompatibility and an interconnected porous structure can be fulfilled by a wide range of materials, reaching equivalent mechanical properties at the same time is still challenging. Biocompatible materials can be found in a large variety of material classes [3]. One example are polymer-based materials, which offer great advantages in terms of customized biodegradation and design [4]. Further to mention are ceramic materials, which also exhibit the aforementioned biodegradation and offer particularly good healing properties for bone defects [5]. However, for fully load-bearing applications only metals fulfill the needed properties, especially regarding strength and 
stiffness [6]. The Laser Powder Bed Fusion (LPBF) process enables the individualized production of high-resolution lattice structures with very fine struts $(<250 \mathrm{~m})[7,8]$ at reasonable cost, and is thus ideal for the production of personalized implants [9]. In particular, the use of zinc ( $\mathrm{Zn})$, magnesium $(\mathrm{Mg})$, iron (Fe) and their alloys, are increasingly coming into focus for orthopaedic applications [10,11]. Although Fe-based implants would biomechanically, and with respect to their corrosion speed[12,13], gain most from increased porosity [14], their limited cytocompatibility is a concern [15]. Nevertheless, in comparison to pure zinc and magnesium, iron has the highest values regarding yield strength and Young's modulus $\left(\sigma_{y, F e} \approx 200-352 \mathrm{MPa}, E_{F e} \approx 188-215 \mathrm{GPa}[16-18] ; \sigma_{y, Z n} \approx 12-32 \mathrm{MPa}, E_{Z n} \approx 43-150\right.$ GPa [12,18,19]; $\sigma_{y, M g} \approx 51 \mathrm{MPa}, E_{M g} \approx 27-35 \mathrm{GPa}$ [20-22]) and offers a large margin for introducing a controlled porosity, which directly influences the strength and stiffness properties of the material. Alloying can further improve the mechanical properties. Adding $\mathrm{Zn}$ to Mg-based alloys increases the yield strength and Young's modulus of the material $[3,13,23]$. Same goes for $\mathrm{Zn}$ alloyed with $\mathrm{Mg}[3,19,24]$, whereas adding aluminum to $\mathrm{Zn}$ based alloys leads to a decrease in stiffness and strength [19].

Examples for $\mathrm{Mg}$ - and $\mathrm{Zn}$-based studies on porous scaffolds can be found i.e at Witte et al. [25], who show the feasibility of producing AM open-porous, biodegradable and biocompatible Mg scaffolds. Li et al. [2] produced AM WE43 scaffolds from diamond unit cells to show the in vitro biodegradation behavior, mechanical properties and biocompatibility. Further, Kopp et al. [26] showed that the pore size of Mg scaffolds influences the long-term stability, while heat treatment especially effects the degradation and mechanical stability. Cockerill et al. [27] used a casting approach to produce porous structures made of pure $\mathrm{Zn}$ and studied the topology, mechanical properties, biodegradation and biocompatibility. Another example is shown by Li et al. [28], who produced scaffolds with a diamond lattice structure via LPBF and studied the static and dynamic biodegradation behavior.

In a physiological environment biodegradable metals usually show a decreasing Young's modulus during the degradation process, due to the progressive absorption of the metallic surface, which consequently leads to a reduction of the strut cross section [29-32]. Since the strut thickness is directly related to the stiffness, the latter will also decrease. Interestingly, during the first days of in vitro corrosion of $\mathrm{Mg}$ (WE43) scaffolds, an increase of around $40 \%$ in the Young's modulus was recently reported [2]. This increase in stiffness is mainly attributed to the formation of a composite cross section, consisting of the base strut and an adherend layer of degradation products. A brief review of the literature shows [3,10,29,31], that the compound of degradation products, which adheres to the surface of the struts, consists for the most parts of hydroxides, phosphates and carbonates, for which only insufficient mechanical properties can be found.

We now used Zn1Mg as an example to investigate the influence of degradation products on the elastic stiffness properties of metallic scaffolds by using analytical calculations and finite element (FE) simulations. For this, first, we focused on the direct influence of the forming substrate layer of degradation products on the axial and bending stiffness of single struts. The corroded strut is modeled as a composite beam with a solid $\mathrm{Zn} 1 \mathrm{Mg}$ base strut and a thin-walled layer of corrosion products of unknown exactly composition. Instead of using concretely quantified values for the Young's modulus for the compound of degradation products, hypothetical multiples of the $\mathrm{Zn} 1 \mathrm{Mg}$ Young's modulus are used. Afterwards, a new scaffold geometry, based on a polar modeling of a $f 2 c c, z$ unit cell is produced and tested, to validate the FE model. Using the validated model, a FE parametric study is done to investigate the influence of the substrate layer thickness and Young's modulus of the compound on the smeared Young's modulus of the scaffold.

\section{Materials and Methods}

\subsection{Biochemical process}

Most of the mineral degradation products of $\mathrm{Zn}$ and $\mathrm{Mg}$ based alloys can be specified as phosphates, carbonates and hydroxides [29], where the phosphates and carbonates form a compound of usually unknown composition that further changes over time. Furthermore, 
a hydroxide layer is forming on the metallic surface. The basic biochemical processes, responsible for this, can be summarized as followed [29,31,32]:

$$
\begin{array}{ll}
\text { Anodic reaction } & \text { Metal } \rightarrow \mathrm{Metal}^{n+}+n\left(e^{-}\right) \\
\text {Cathodic reaction } & 2 \mathrm{H}_{2} \mathrm{O}+2 e^{-} \rightarrow 4 \mathrm{OH}^{-}+\mathrm{H}_{2} \\
& 2 \mathrm{H}_{2} \mathrm{O}+\mathrm{O}_{2}+4 e^{-} \rightarrow 4 \mathrm{OH}^{-} \\
\text {Product formation } & \mathrm{Metal}^{n+}+n\left(\mathrm{OH}^{-}\right) \rightarrow \operatorname{Metal}(\mathrm{OH})_{n} \\
\text { Product dissolution } & \operatorname{Metal}(\mathrm{OH})_{n}+2 \mathrm{Cl}^{-} \rightarrow \operatorname{Metal}(\mathrm{Cl})_{2}+2 \mathrm{OH}^{-}
\end{array}
$$

Figure 1 shows a simplified schematic of the degradation process. The human body fluid releases an anodic reaction and the free electrons undergo a cathodic reaction under the release of hydrogen and hydroxide ions, which form together with the metal a hydroxide layer on the surfaces of the struts. From equivalent reactions, phosphates and carbonates form on the struts surfaces [29]. These processes are responsible for an increase in stiffness during the early phases of the corrosion process [2]. Later, chloride ions start the dissolution of the biodegradable metal to cause a decrease of the cross-sectional strut diameter of the scaffold.

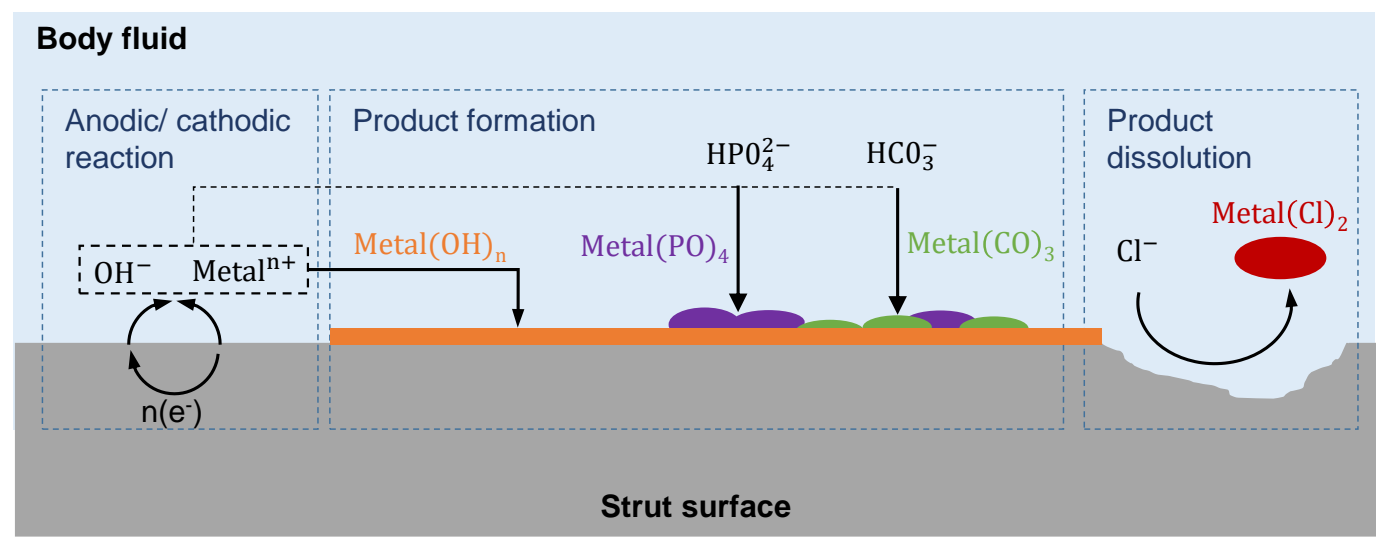

Figure 1. Schematic process sketch of the degradation process of absorbable metals according to Han et al. and $\mathrm{Li}[29,31]$.

\subsection{Scaffold manufacturing}

The LPBF (Laser Powder Bed Fusion) experiments are performed on an AconityMINI system designed by Aconity3D (Herzogenrath, Germany), which is specifically developed for laboratory use. This system is characterized by an adapted gas flow management to remove the resulting process fume for materials with low melting and evaporating temperature (e.g., zinc: $692 \mathrm{~K}, 1180 \mathrm{~K}$ ). These materials tend to produce a large amount of process fume during manufacture. The beam source is a single-mode fiber laser (wavelength of $1064 \mathrm{~nm}$ ) with up to $400 \mathrm{~W}$ of power output. Samples are manufactured on zinc baseplate using a bidirectional scanning strategy with 90 rotations between consecutive layers. The energy input during exposure is controlled by the selected process parameters (laser power $\left(P_{L}\right)$, layer thickness $\left(D_{s}\right)$, scanning speed $\left(v_{s}\right)$, and hatch distance $\left.\left(\Delta y_{s}\right)\right)$. The volume energy density $\left(E_{V}\right)$ is calculated as followed [33]:

$$
E_{V}=\frac{P_{L}}{D_{S} v_{s} \Delta y_{s}}
$$

Within the scope of this work, all AM scaffolds are manufactured with a constant layer thickness of $30 \mathrm{~m}$ an $E_{V}$ is set for all scaffolds to $133 \mathrm{~J} / \mathrm{mm}^{3}$. The scaffolds were afterwards sandblasted with 2.5 bar, to remove adhering powder particles.

\subsection{Scaffold geometry}

Figure 2 shows the scaffold geometry, which is used for the FE study and validation 
tests. A modified polar $\mathrm{f} 2 \mathrm{cc}, \mathrm{z}$ unit cell is used. A total number of four cells in radial direction $\left(n_{1,2}=4\right)$, a total number of 17 cells in circumferential direction $(m=17)$ and a total number of $12\left(n_{3}=12\right)$ cells in height direction is used. The scaffold has a total height of $h=12 \mathrm{~mm}$ and a diameter of $d=10 \mathrm{~mm}$. The nominal strut radius is $r_{S}=0.1 \mathrm{~mm}$. The cell width $b$ results from $b=\left(d-2 R_{m}\right) /\left(2 n_{1,2}\right)=0.9 \mathrm{~mm}$, where $R_{m}=1.4 \mathrm{~mm}$ is the radius of central cavity, or rather the inner radius of the first cell ring, measured at the cells edges. Since the cells only approximate a circle, the radial position of the midpoint of the cells side faces lies at $r_{m, i}=r_{i} \cos (\varphi / 2)$ for the inner face and $r_{m, a}=r_{a} \cos (\varphi / 2)$ for the outer face, where $r_{i}$ is the inner radius of the cell edges and $r_{a}$ is the outer radius of the cell edges and $\varphi=2 \pi / m$ is the proportion that a cell has in the total circumference. The strut inclination $\omega$ of the circumferential diagonal struts can be calculated for the inner diagonals of each cell ring $\left(\omega_{i}\right)$ and for the outer diagonals of each cell ring $\left(\omega_{0}\right)$ as followed:

$$
\omega_{i}=\arctan \left(h / b_{i}\right) ; \omega_{o}=\arctan \left(h / b_{0}\right)
$$

The radial orientated diagonals strut inclination is equal for all cell rings and results from $\omega_{r}=\tan (h / b)$. Table 1 sums the resulting geometric parameters of the scaffold. It should be noticed that for the outer rings, the strut inclinations of the diagonals get lower 45 , which usually leads to unfavorable conditions in the AM process. By an optimization of the manufacturing parameters, see Section 2.2 for reference, and the good processability of the material, it was nevertheless possible to produce flat angles, as shown in Figure 3 . The strut diameter of the manufactured scaffolds were measured at random positions, resulting in $r_{s} \approx 0.092-0.106 \mathrm{~mm}$, which lies in an acceptable tolerance range of the nominal strut radius.

Table 1. Resulting geometric parameters of the scaffold used for this study $\left(R_{m}=1.4 \mathrm{~mm}\right)$; $i$ defines the actual ring, starting from the middle with $i=1$ according to Figure 2

\begin{tabular}{ccccccccc}
\hline$i$ & $r_{i}[\mathrm{~mm}]$ & $r_{m, i}[\mathrm{~mm}]$ & $b_{i}[\mathrm{~mm}]$ & $\omega_{i}\left[^{\circ}\right]$ & $r_{o}[\mathrm{~mm}]$ & $r_{m, o}[\mathrm{~mm}]$ & $b_{o}[\mathrm{~mm}]$ & $\omega_{o}\left[^{\circ}\right]$ \\
\hline $\mathbf{1}$ & 1.4 & 1.376 & 0.515 & 62.8 & 2.3 & 2.261 & 0.845 & 49.8 \\
$\mathbf{2}$ & 2.3 & 2.261 & 0.845 & 49.8 & 3.2 & 3.146 & 1.176 & 40.4 \\
$\mathbf{3}$ & 3.2 & 3.146 & 1.176 & 40.4 & 4.1 & 4.030 & 1.507 & 33.6 \\
$\mathbf{4}$ & 4.1 & 4.030 & 1.507 & 33.6 & 5.0 & 4.917 & 1.838 & 28.6 \\
\hline
\end{tabular}
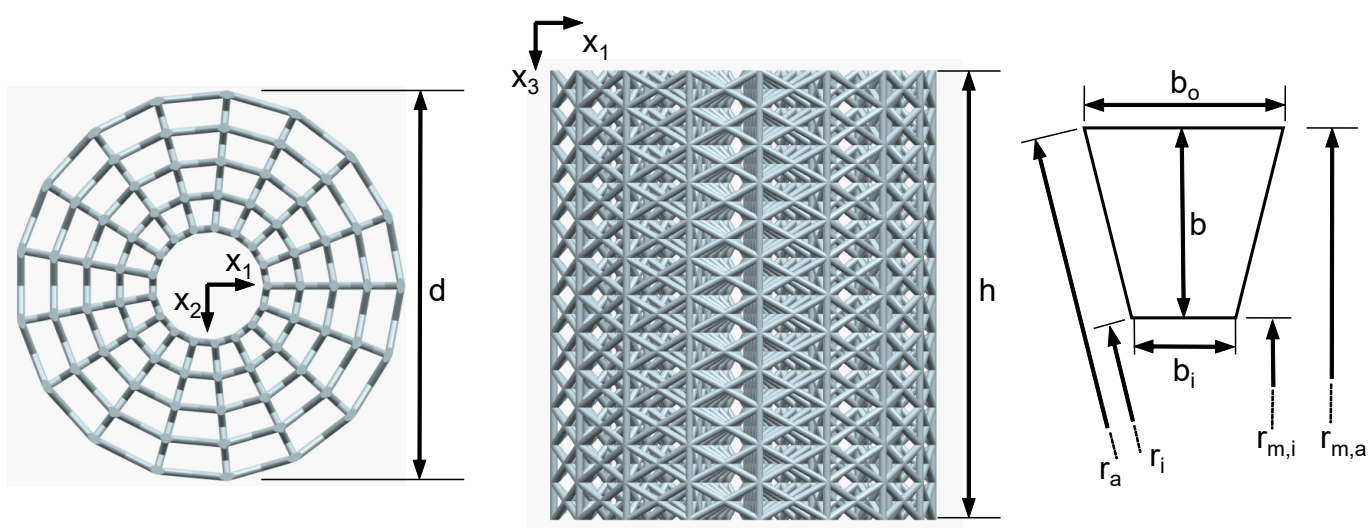

Figure 2. Scaffold geometry used for the study.

\subsection{Materials and mechanical properties}

This study focuses a Zinc-Magnesium alloy $(\mathrm{Zn} 1 \mathrm{Mg})$. The elastic material properties used for the numerical and analytical studies are based on literature data [19,34-36]. Validation tests are done on additively manufactured $\mathrm{Zn} 1 \mathrm{Mg}$ scaffolds. Furthermore, 

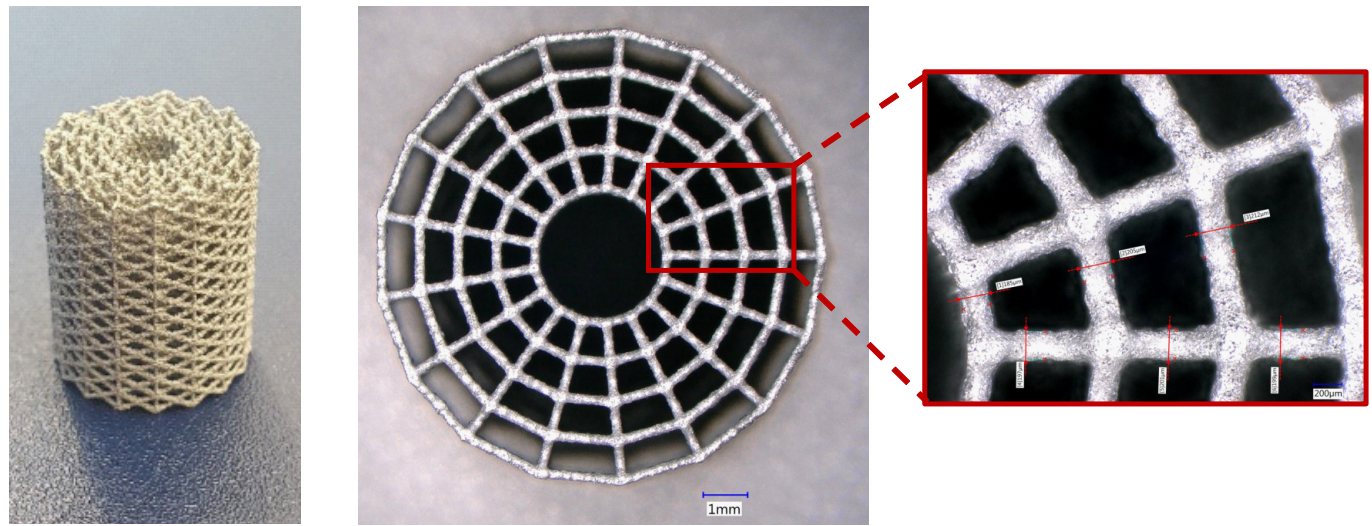

Figure 3. Resulting LPBF produced scaffold used for the physical evaluation.

this study is based on a previous study using WE43 scaffolds [2]. Young's modulus and yield strength of $\mathrm{Zn} 1 \mathrm{Mg}$ were reported by Yang et al. [19]. Young's modulus of $\mathrm{Zn} 1 \mathrm{Mg}$ is documented to be $E_{Z n 1 M g} \approx 19 \mathrm{GPa}$ and yield strength $\sigma_{y, Z n 1 M g} \approx 74 \mathrm{MPa}$. The mechanical properties for $\mathrm{Zn} 1 \mathrm{Mg}$ have been extracted via tensile tests. Both, the zinc content as well as the magnesium content will take part in the biochemical reaction process. Material properties for $\mathrm{Zn}(\mathrm{OH})_{2}, \mathrm{Mg}(\mathrm{OH})_{2}, \mathrm{ZnCO}_{3}$ and $\mathrm{MgCO}_{3}$ from degradation processes are not sufficiently documented in the literature, but can be approximated by extrapolating data i.e. from Ulutan et al. [34], who reported values for the Young's modulus of $\mathrm{Mg}(\mathrm{OH})_{2}$ of $E_{\mathrm{Mg}(\mathrm{OH})_{2}}=64 \mathrm{GPa}$, Ulian et al. [35] reporting throughout anisotropic behavior an $E_{\mathrm{Mg}(\mathrm{OH})_{2}} \approx 64-180 \mathrm{GPa}$, or Yao et al. [36] reporting the Young's modulus of $\mathrm{MgCO}_{3}$ to be $E_{\mathrm{MgCO}_{3}} \approx 150-260 \mathrm{GPa}$. For $\mathrm{Mg}(\mathrm{PO})_{4}$ and the degradation products of $\mathrm{Zn}$, insufficient data were found. Due to the poor data concerning material properties and proportions of the composite material, hypothetical Young's moduli are defined by multiples of the base materials Young's modulus, which is adequate for the analytical and numerical investigations concerning the general influence.

\subsection{Analytical Model}

The metallic strut and the enclosing compound of degradation products can be modeled as a composite beam. Here, the metallic core is surrounded by a thin-walled mineral cross section, which is idealized to be perfectly round in the following, and is demonstrated in Figure 4. Afterwards, the axial and bending stiffness of a composite strut can be calculated by a summation of the individual layer stiffnesses. The resulting equivalent composite axial stiffness $\overline{E A}$ can be calculated as followed:

$$
\overline{E A}=\sum E_{j} A_{j}=E_{s} r_{s}^{2} \pi+E_{\mathrm{sub}}\left(2 r_{s} t_{\mathrm{sub}}+t_{\mathrm{sub}}^{2}\right) \pi,
$$

where $E_{s}$ is the base materials Young's modulus, $E_{\text {sub }}$ is the Young's modulus of the compound of degradation products in the substrate layer, $r_{s}$ is the inner radius of the substrate layer, or rather the base strut radius, and $t_{\text {sub }}$ is the thickness of the substrate layer. For the equivalent composite bending stiffness $\overline{E J}$ results:

$$
\overline{E J}=\sum E_{j} J_{j}=E_{s} \frac{\pi}{4} r_{s}^{4}+E_{\text {sub }} \frac{\pi}{4}\left(\left(r_{s}+t_{\text {sub }}\right)^{4}-r_{s}^{4}\right) .
$$

\subsection{Finite Element Model}

For the FE calculations Abaqus/Standard with python scripting for model creation is used. The scaffolds are meshed using 3-node quadratic beam elements (B32). A convergence study shows, that using five elements per strut gives sufficient results. Linear elastic material behavior and a static, displacement controlled step is used. A displacement of $u=1 \mathrm{~mm}$ in axial direction ( $x_{3}$-direction) of the scaffold is applied. The summation of 


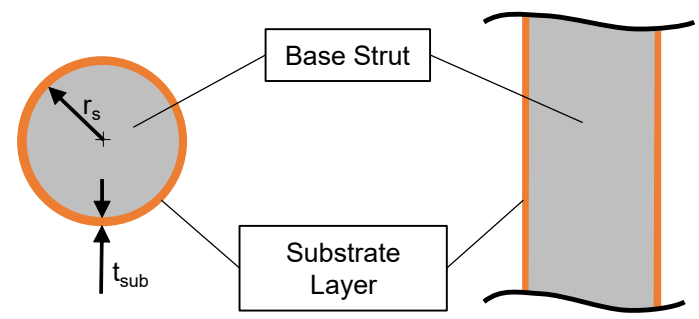

Figure 4. Cross section of the idealized corroded strut; in grey: base strut, in orange: compound of degradation/ reaction products.

the nodal reaction forces in axial direction $F_{3}$ is measured. The resulting stiffness can be calculated from $(E A)=F_{3} h / u_{3}$. Since for beam elements no composite cross section can be defined in Abaqus/Standard, a generalized beam profile is used. Stiffnesses are defined according to Equation 3 and Equation 4. To validate the beam formulation, a single strut under compression and bending is modeled using a) a 3D-volume mesh with a hybrid meshing strategy using 10-node quadratic tetrahedron (C3D10) and 20-node quadratic hexagonal (C3D20) elements and b) the aforementioned beam modeling strategy. For good mesh quality 48 elements in circumferential direction and five elements in radial direction plus one additional element for the substrate layer are used. According to the scaffold mesh, for the single strut beam model a total number of ten 3-node quadratic beam elements (B32) is used. Both models are show in Figure 5. The base strut radius is set to $r_{s}=0.1 \mathrm{~mm}$ and the substrate layer thickness $t_{\text {sub }}=0.01 \mathrm{~mm}$ (see Figure 4 for reference). The strut length is $l=5 \mathrm{~mm}$. The beam model cross section is defined with a generalized beam section according to the scaffold model. Both, struts under axial compression and bending are examined. For the axial loaded strut a simply supported beam and for the bending model a cantilever beam model is used.

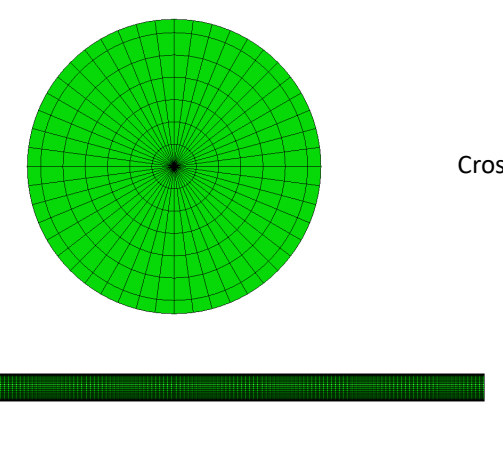

(a) Solid mesh

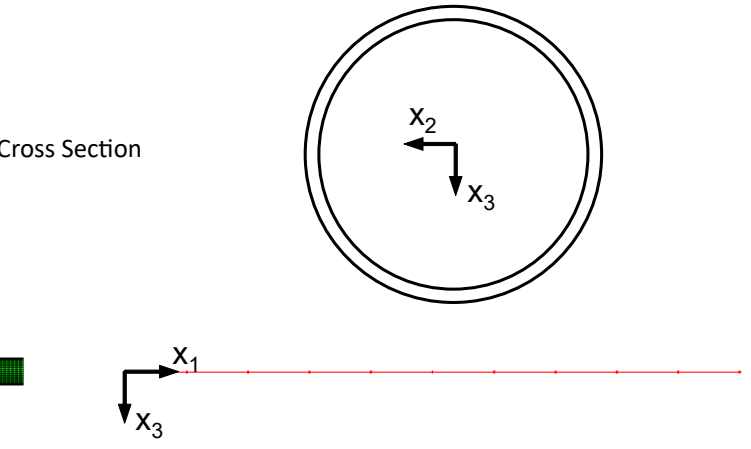

(a) Beam mesh

Figure 5. Finite Element Mesh; (a) solid model, (b) beam model with schematic cross section.

\subsection{Experimental Setup}

To validate the FE-model, compression tests on equivalent LPBF (Laser Powder Bed Fusion) produced $\mathrm{Zn} 1 \mathrm{Mg}$ polar scaffolds are done. A total number of two specimens is tested. The tests are done on an Instron 5567 electric tensile/compression testing machine with $30 \mathrm{kN}$ load cell. The tests are performed displacement controlled with a crosshead speed of $\dot{u}=0.2 \mathrm{~mm} / \mathrm{min}$. The crosshead displacement and load are documented. Since small shifts in the test setup lead to differences between the real and the crosshead displacement, the tests are monitored via DIC-technique (Direct Image Correlation) using an Aramis 4M system by GOM. By this, the real displacement of the specimen can be measured. Figure 6 shows the setup of the compression tests. 


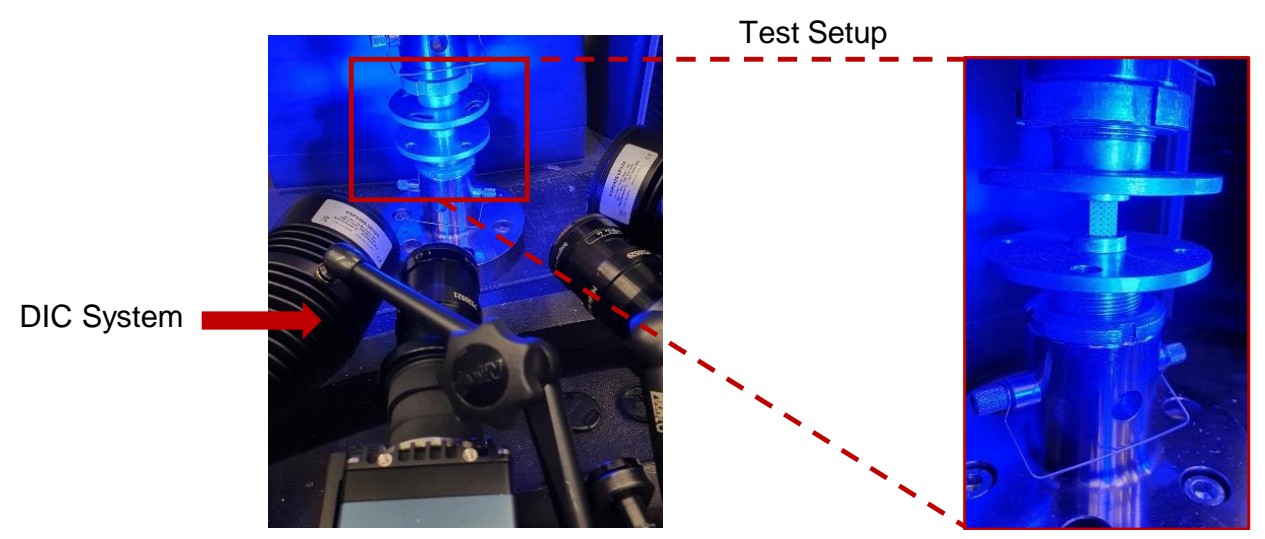

Figure 6. Experimental setup for compression tests on AM Zn1Mg scaffolds.

\section{Results}

\subsection{Analytical Results}

Figure 7 shows the results of the analytical calculations for the $\mathrm{Zn} 1 \mathrm{Mg}$ single struts under axial compression. Shown is resulting composite Young's modulus $E$ as a function of the substrate layer thickness $t_{\text {sub }}$ for different strut radii $r_{s}(50 \mu \mathrm{m}-250 \mu \mathrm{m})$. Furthermore, Figure 7 a) shows the resulting absolute composite Young's modulus (left axis) and relative increase $E / E_{Z n 1 M g}$ ) (right axis) for a Young's modulus twice as high, $b$ ) three times as high, c) four times as high and d) five times as high as the base materials Young's modulus. It can be noticed that the thinner the struts and the thicker the substrate layer, the higher the resulting composite axial stiffness of the strut. Especially for smaller strut radii, i.e. $r_{s}=50 \mu \mathrm{m}$, as well as for small substrate thicknesses, the effect of an increase in axial stiffness is clearly visible. Same applies for high Young's moduli of the substrate layer.

Figure 8 shows the results for the analytical observations of the $\mathrm{Zn} 1 \mathrm{Mg}$ single struts under bending. Shown is the resulting composite bending stiffness $E J$ as a function of the substrate layer thickness $t_{s u b}$ for different substrate Young's moduli $E_{s u b}$, which is set to 2-5 times the base materials Young's modulus $E_{Z n 1 M g}$. Furthermore, Figure 8 shows the resulting absolute composite bending stiffness $E J$ (left axis) and relative increase $E J /(E J)_{\mathrm{Zn1Mg}}$ ) (right axis) for a) a base strut radius $\left.r_{s}=50 \mu \mathrm{m}, \mathrm{b}\right) r_{s}=100 \mu \mathrm{m}$, c) $r_{s}=150 \mu \mathrm{m}$ and d) $r_{s}=200 \mu \mathrm{m}$. With increasing substrate layer thickness and higher substrate Young's modulus, a higher increase in bending stiffness can be observed. Especially for small strut radii, like $r_{s}=50 \mu \mathrm{m}$, very high increases in bending stiffness can be achieved. This is not only the case for high moduli of the substrate layer, but also in the case when the composite of degradation products has the same Young's modulus.

\subsection{Finite Element Results}

\subsubsection{Single strut simulations}

Figure 9 shows the results of the FE simulations of single struts under axial compression. For both, the base strut and the corroded strut, the axial reaction force RF1 shows nearly equal values and the difference lies under $0.02 \%$. In Figure 10 the comparison for the bending loaded struts is presented. In both cases the results of the beam model and the solid model are in good agreement. For the base struts, the difference regarding reaction force $R F$ and reaction moment $R M$ lies at around $1 \%$. For the corroded struts, the difference is lower than $0.03 \%$. Furthermore, especially in the case of the corroded strut, the calculation time can be massively decreased using a beam modeling approach.

\subsubsection{Whole scaffold modeling}

Figure 11 shows the results of the FE Scaffold parametric study. Shown is the resulting smeared Young's modulus $E$ of the scaffold, which results from dividing the axial reaction forces by the projected cross section of the whole scaffold $A$, as a function of the base strut 
radius $r_{s}$ for different thicknesses of the substrate layer $t_{s u b}$ and (a) a compound Young's modulus of the substrate layer of $E_{s u b}=19 \mathrm{GPa}$ (equal to $E_{Z n 1 M g}$ ), (b) $E_{s u b}=38 \mathrm{GPa}$, (c) $E_{s u b}=57 \mathrm{GPa}$ and (d) $E_{s u b}=76 \mathrm{GPa}$. The stiffness grows exponentially as a function of the strut diameter and is clearly more pronounced the higher the Young's modulus of the compound of the substrate. A significant increase in the axial stiffness of the scaffolds can be observed from all hypothetical Young's moduli of the substrate. Table 2-5 sums the quantitative results for the respective Young's moduli. It can be seen that already for a base materials equivalent Young's modulus of the substrate, small substrate thicknesses of a few microns and small strut radii lead to an increase in stiffness of $22 \%-85 \%$. The effect increases significantly when considering higher layer thicknesses and higher stiffnesses of the substrate layer.

Table 2. Percentage increase of the smeared Young's modulus $E$ for $E_{\text {sub }}=19 \mathrm{GPa}$

\begin{tabular}{lccccc}
\hline \multirow{2}{*}{$t_{\text {sub }}[\mu \mathrm{m}]$} & \multicolumn{5}{c}{$r_{s}[\mathrm{~mm}]$} \\
& 0.05 & 0.1 & 0.15 & 0.2 & 0.25 \\
\hline $\mathbf{5}$ & $22 \%$ & $11 \%$ & $8 \%$ & $6 \%$ & $4 \%$ \\
$\mathbf{1 0}$ & $46 \%$ & $23 \%$ & $15 \%$ & $11 \%$ & $9 \%$ \\
$\mathbf{2 0}$ & $102 \%$ & $49 \%$ & $35 \%$ & $23 \%$ & $18 \%$ \\
\hline
\end{tabular}

Table 3. Percentage increase of the smeared Young's modulus $E$ for $E_{\text {sub }}=38 \mathrm{GPa}$

\begin{tabular}{lccccc}
\hline \multirow{2}{*}{$t_{\text {sub }}[\mu \mathrm{m}]$} & 0.05 & 0.1 & 0.15 & 0.2 & 0.25 \\
\hline $\mathbf{5}$ & $43 \%$ & $22 \%$ & $14 \%$ & $11 \%$ & $8 \%$ \\
$\mathbf{1 0}$ & $91 \%$ & $44 \%$ & $29 \%$ & $22 \%$ & $17 \%$ \\
$\mathbf{2 0}$ & $201 \%$ & $95 \%$ & $61 \%$ & $45 \%$ & $35 \%$ \\
\hline
\end{tabular}

Table 4. Percentage increase of the smeared Young's modulus $E$ for $E_{\text {sub }}=57 \mathrm{GPa}$

\begin{tabular}{lccccc}
\hline \multirow{2}{*}{$t_{\text {sub }}[\mu m]$} & 0.05 & 0.1 & 0.15 & 0.2 & 0.25 \\
\hline $\mathbf{5}$ & $64 \%$ & $32 \%$ & $21 \%$ & $16 \%$ & $13 \%$ \\
$\mathbf{1 0}$ & $136 \%$ & $66 \%$ & $43 \%$ & $32 \%$ & $25 \%$ \\
$\mathbf{2 0}$ & $300 \%$ & $140 \%$ & $90 \%$ & $66 \%$ & $52 \%$ \\
\hline
\end{tabular}

Table 5. Percentage increase of the smeared Young's modulus $E$ for $E_{\text {sub }}=76 \mathrm{GPa}$

\begin{tabular}{lrrrrr}
\hline \multirow{2}{*}{$t_{\text {sub }}[\mu \mathrm{m}]$} & 0.05 & 0.1 & 0.15 & 0.2 & 0.25 \\
\hline $\mathbf{5}$ & $85 \%$ & $42 \%$ & $28 \%$ & $21 \%$ & $17 \%$ \\
$\mathbf{1 0}$ & $180 \%$ & $87 \%$ & $57 \%$ & $42 \%$ & $34 \%$ \\
$\mathbf{2 0}$ & $353 \%$ & $164 \%$ & $106 \%$ & $78 \%$ & $61 \%$ \\
\hline
\end{tabular}

\subsection{Confirmation by physical evaluation}

Figure 12 shows the results of the two tested scaffolds under axial compression in comparison to the FE result. The tests show reproducible behavior regarding the stiffness. The smeared Young's modulus of the scaffolds can be calculated in the linear region of the load displacement curves by $E=F h /(A u)$, where $F$ is the measured force in the machines 
load cell, $h$ is the total height of the scaffold, $A$ is the projected smeared cross section of the scaffold and $u$ is the displacement associated with the measured force. From the tests a Youngs's modulus of approximately $E_{\text {test }} \approx 1125 \mathrm{MPa}$ can be determined, measured in the area between $600-800 \mathrm{~N}$. From the FE model a Young's modulus of $E_{F E}=1258$ $\mathrm{MPa}$ can be extracted. Furthermore, the FE model shows that for loads smaller $800 \mathrm{~N}$, nowhere the strut-stresses have exceeded the yield point. The slight differences could be attributed to local deviations in the strut diameter of the AM scaffolds, as shown in Section 2.3 respectively Figure 3. Furthermore, the modeling using beam elements neglects the accumulation of material in the nodes of the real scaffold. Furthermore, the used Young's modulus is based on literature data and it is well known that Young's moduli of AM materials tend to show slight differences (see also Section 1). Nevertheless, the tests show that the FE model based on beam elements provides sufficiently accurate results in terms of the resulting smeared axial stiffness and can be used for the parametric study.

\section{Discussion}

We investigated the influence of degradation products on the elastic stiffness properties of biodegradable metallic scaffolds. For this, a hypothetical compound of degradation products was modeled as a thin-walled layer with a homogeneous cross section. Since there is no sufficient database, yet, for the mechanical properties of the degradation products, hypothetical Young's moduli were defined using multiples of the Young's modulus of the base material. By this, the influence of the substrate layer as a function of the thickness and Young's modulus of the layer could be investigated. This was done using analytical models and finite element simulations on single struts, to show the direct influence of the substrate layer on the axial and bending stiffness. Two modeling approaches were contrasted for the FE simulations, first a meshing strategy using a 3D volume mesh and second using beam elements. Both approaches show concurring results. For this reason, the beam model was used for the parametric study on whole lattice scaffold geometries, due to the enormous difference regarding the calculation time. To validate the FE model compression tests on two LPBF produced scaffolds were done.

From the single strut investigations can be concluded, that depending on the substrates Young's modulus and the ratio of strut radius to thickness of the substrate layer, significantly increases of the composite axial and bending stiffness is expected. The effect intensifies, the smaller the base strut radius in the initial state is. This applies as well as for relatively low Young's moduli of the substrate layer as for very high Young's moduli. The compression tests on LPBF produced scaffolds show reproducible results and furthermore equivalent smeared Young's moduli in the FE model and physical tests. For this reason, a parametric study on the tested geometry was done, by varying the substrate layer thickness and the Young's moduli of the compound of the degradation products in the substrate layer, to study the influence of the substrate layer on the smeared Young's modulus of complex scaffold geometries. Our results show that an enormous increase in stiffness can be expected even for complex geometries. Furthermore, compared to the separated reflection of the influence of the substrate layer on axial and bending stiffness of single struts, the effect of a stiffness increase is clearly more pronounced in the case of scaffold geometries. This is mainly attributable to the combined loading in compression and bending of the struts, which ultimately has a direct effect on the smeared Young's modulus of the scaffold.

In conclusion, our analytical and numerical modeling approach basically confirmed earlier assumptions by Li et al. [2], that the increase in stiffness of corrosion product layer-coated AM WE43 is indeed due to formation of a composite beam of base strut and substrate layer. Nevertheless, our results have to be validated by further investigations on corroded single struts or equal.

Author Contributions: JB performed most of the analytical analyses, FE modeling, physical testing, and drafted the paper. JB, MV and HJ contributed to the design of the scaffold, while MV produced them . HJ initiated and supervised the study, including the analyses. JHS and KUS contributed their 
extensive experience, gave advice regarding the content and the manuscript. All authors co-edited, reviewed, and approved the final version of the manuscript.

Funding: Parts of this work were supported by the Federal Ministry of Education and Research (BMBF) and the Ministry of Culture and Science of the State of North Rhine-Westphalia (MKW) under the Excellence Strategy of the Federal Government and the Länder (OPSF597).

Institutional Review Board Statement: Not applicable.

Informed Consent Statement: Not applicable.

Data Availability Statement: The data presented in this study are available on request from the corresponding author.

Acknowledgments: The authors thank the BMBF for funding of the work.

Conflicts of Interest: The authors declare no conflicts of interest. 


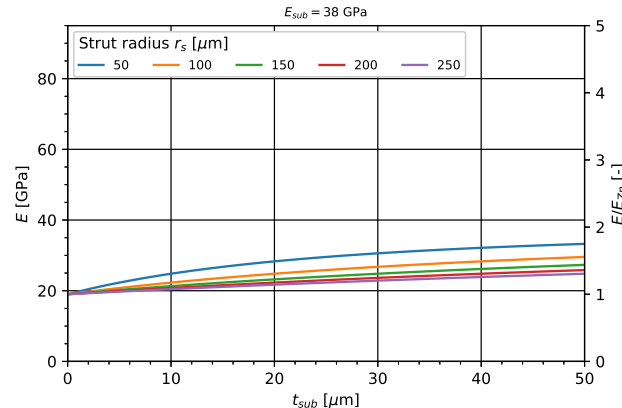

(a) $E_{s u b}=2 \cdot E_{Z n 1 M g}$

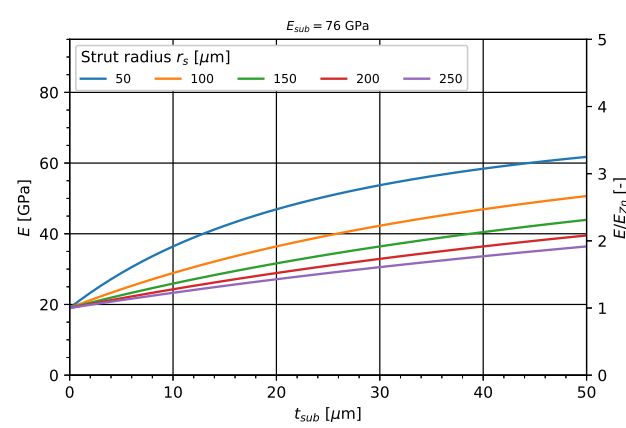

(c) $E_{\text {sub }}=4 \cdot E_{\mathrm{Zn} 1 \mathrm{Mg}}$

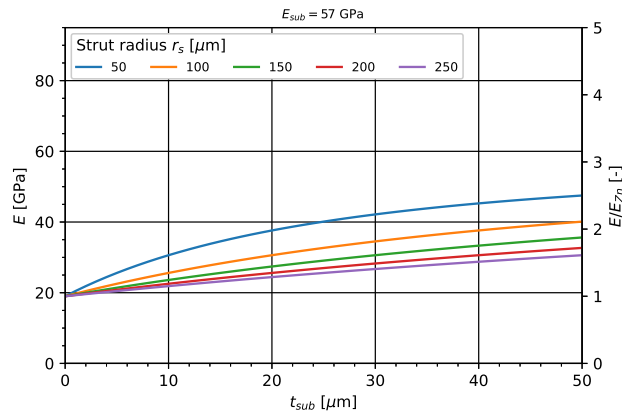

(b) $E_{s u b}=3 \cdot E_{Z n 1 M g}$

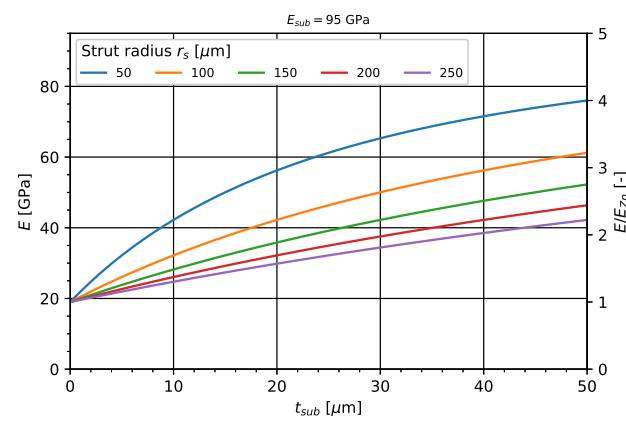

(d) $E_{\text {sub }}=5 \cdot E_{Z n 1 M g}$

Figure 7. Analytical calculation of the axial stiffness of a single composite strut for varying parameters of the substrate layer.

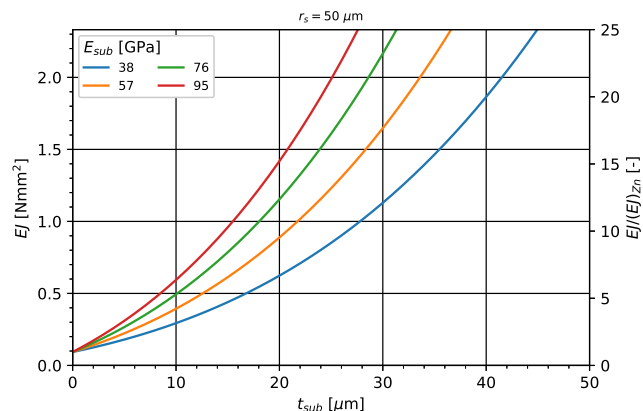

(a) $r_{s}=50 \mu \mathrm{m}$

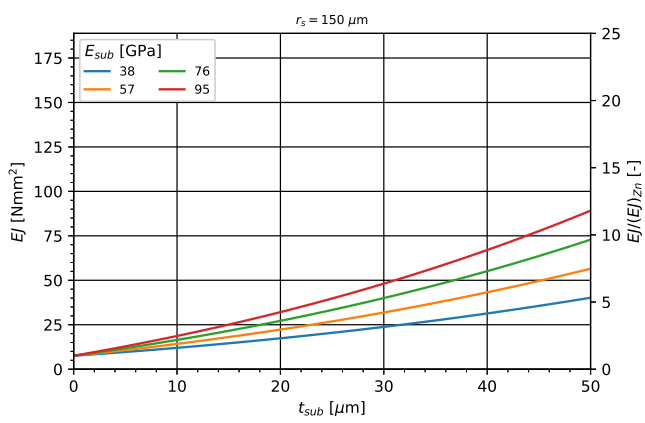

(c) $r_{\mathrm{S}}=150 \mu \mathrm{m}$

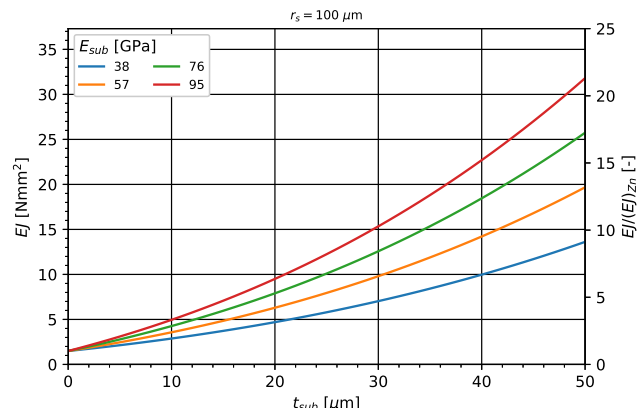

(b) $r_{s}=100 \mu \mathrm{m}$

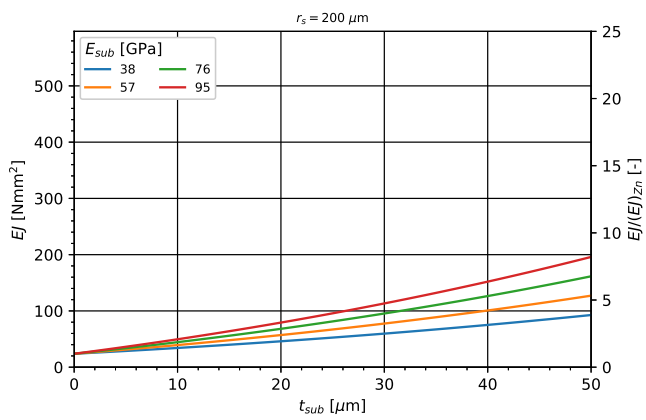

(d) $r_{s}=200 \mu \mathrm{m}$

Figure 8. Analytical calculation of the bending stiffness of a single composite strut for varying parameters of the substrate layer. 

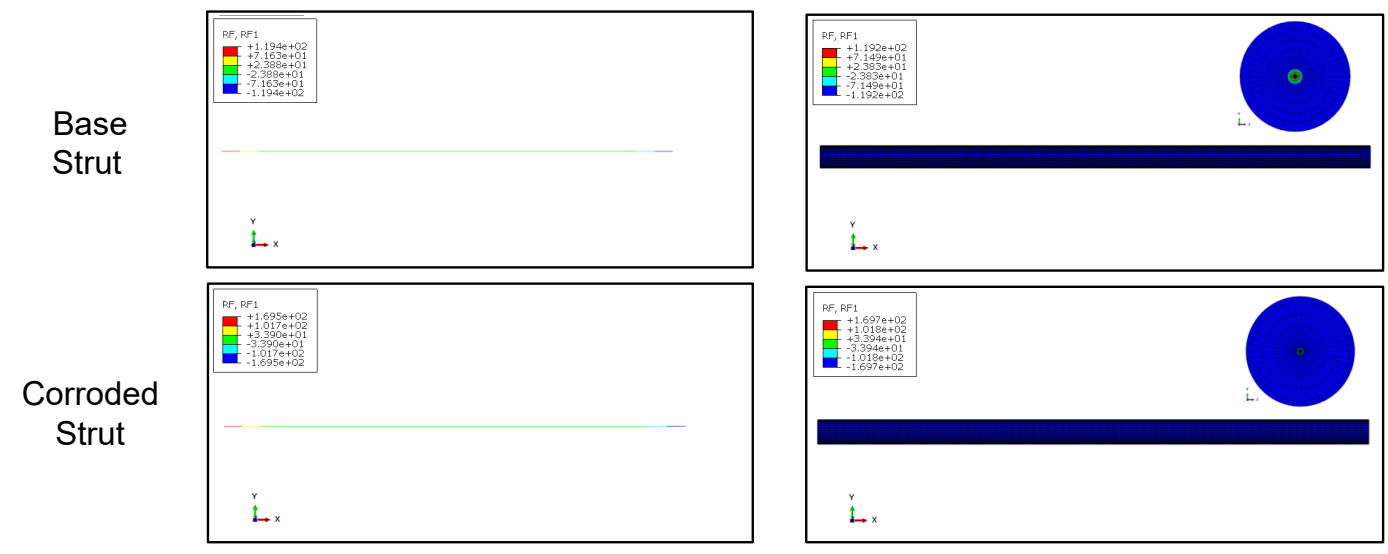

Figure 9. Comparison of modeling approaches for base and corroded strut under axial compression; left: beam elements, right: solid elements.

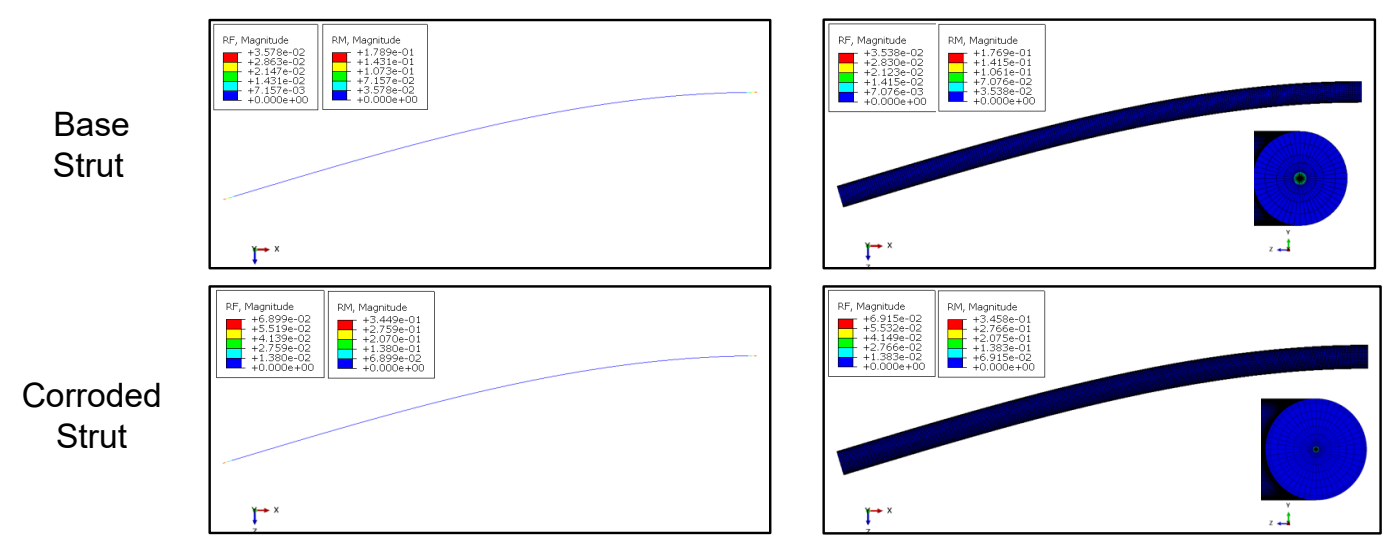

Figure 10. Comparison of modeling approaches for base and corroded strut under bending; left: beam elements, right: solid elements. 


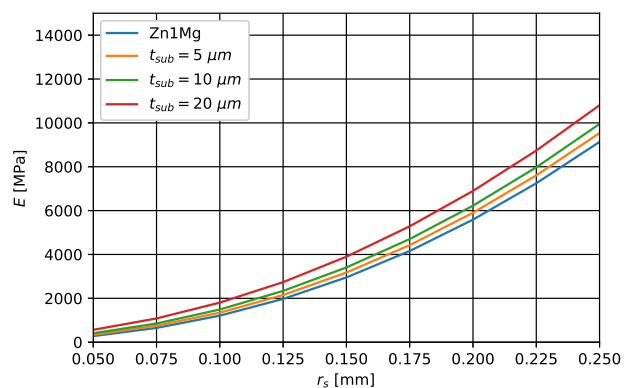

(a) $E_{\text {sub }}=19 \mathrm{GPa}$

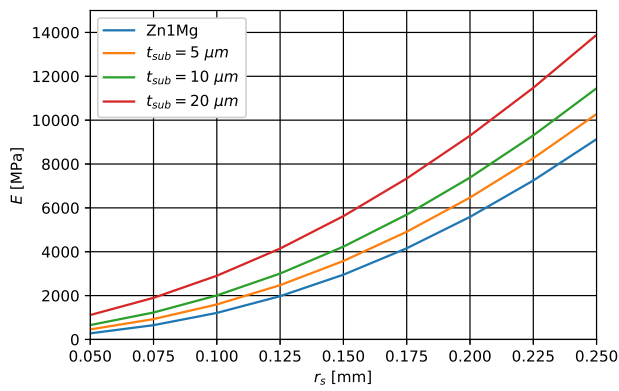

(c) $E_{\text {sub }}=57 \mathrm{GPa}$

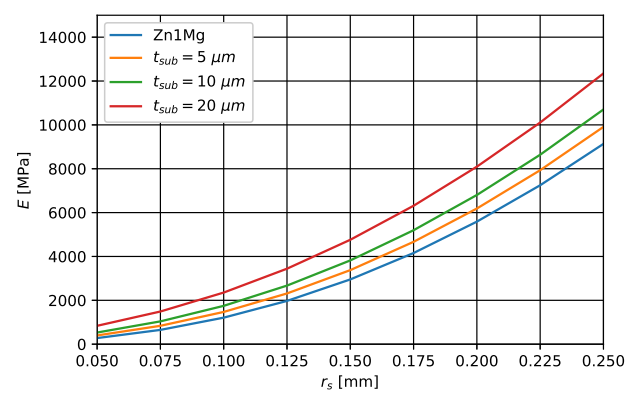

(b) $E_{\text {sub }}=38 \mathrm{GPa}$

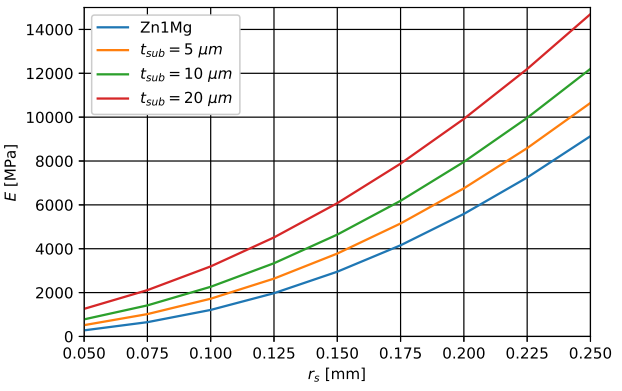

(d) $E_{\text {sub }}=76 \mathrm{GPa}$

Figure 11. Results of the FE simulations of corroded scaffolds for varying parameters.

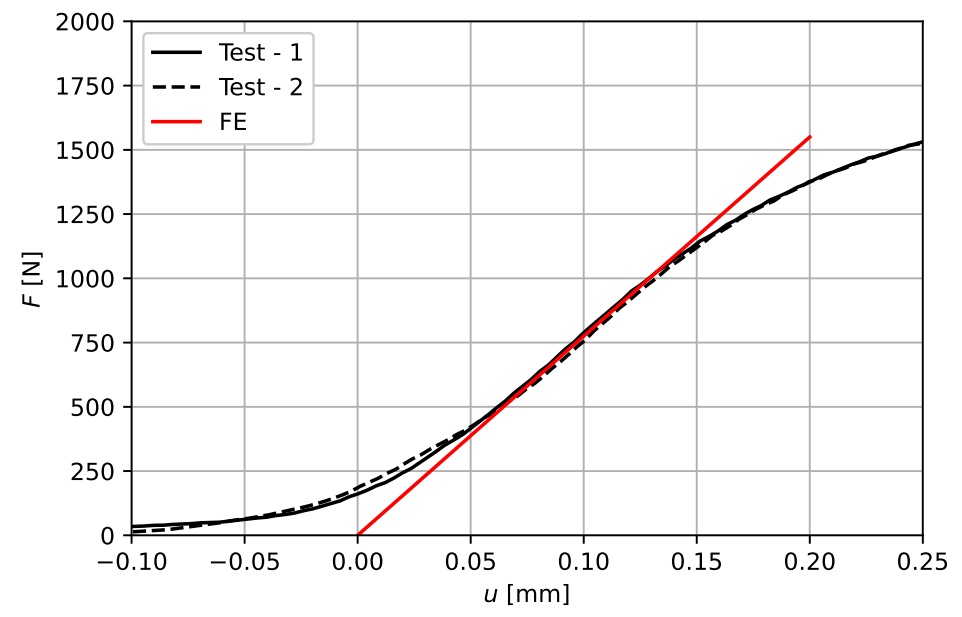

Figure 12. Validation of FE model: Resulting load-displacement curve of two tested LPBF produced scaffolds and equivalent FE model. 


\section{References}

1. Böstman, O.; Pihlajamäki, H. Clinical biocompatibility of biodegradable orthopaedic implants for internal fixation: a review. Biomaterials 2000, 21, 2615-2621. doi:10.1016/s0142-9612(00)00129-0.

2. Li, Y.; Zhou, J.; Pavanram, P.; Leeflang, M.A.; Fockaert, L.I.; Pouran, B.; Tümer, N.; Schröder, K.U.; Mol, J.M.C.; Weinans, H.; Jahr, H.; Zadpoor, A.A. Additively manufactured biodegradable porous magnesium. Acta biomaterialia 2018, 67, 378-392. doi:10.1016/j.actbio.2017.12.008.

3. Jahr, H.; Li, Y.; Zhou, J.; Zadpoor, A.A.; Schröder, K.U. Additively Manufactured Absorbable Porous Metal Implants - Processing, Alloying and Corrosion Behavior. Frontiers in Materials 2021, 8, 292. doi:10.3389/fmats.2021.628633.

4. Liu, X.; Ma, P.X. Polymeric scaffolds for bone tissue engineering. Annals of biomedical engineering 2004, 32, 477-486. doi:10.1023/b:abme.0000017544.36001.8e.

5. Seitz, H.; Rieder, W.; Irsen, S.; Leukers, B.; Tille, C. Three-dimensional printing of porous ceramic scaffolds for bone tissue engineering. Journal of biomedical materials research Part B - Applied biomaterials 2005, 74B, 782-788. doi:10.1002/jbm.b.30291.

6. Chen, Q.; Thouas, G.A. Metallic implant biomaterials. Materials Science and Engineering: R: Reports 2015, 87, 1-57. doi:10.1016/j.mser.2014.10.001.

7. Cutolo, A.; Engelen, B.; Desmet, W.; van Hooreweder, B. Mechanical properties of diamond lattice Ti-6Al-4V structures produced by laser powder bed fusion: On the effect of the load direction. Journal of the Mechanical Behavior of Biomedical Materials 2020, 104, 103656. doi:10.1016/j.jmbbm.2020.103656.

8. Gümrük, R.; Mines, R.; Karadeniz, S. Static mechanical behaviours of stainless steel micro-lattice structures under different loading conditions. Materials Science and Engineering: A 2013, 586, 392-406. doi:10.1016/j.msea.2013.07.070.

9. Yan, Q.; Dong, H.; Su, J.; Han, J.; Song, B.; Wei, Q.; Shi, Y. A Review of 3D Printing Technology for Medical Applications. Engineering 2018, 4, 729-742. doi:10.1016/j.eng.2018.07.021.

10. Li, Y.; Jahr, H.; Zhou, J.; Zadpoor, A.A. Additively manufactured biodegradable porous metals. Acta biomaterialia 2020, 115, 29-50. doi:10.1016/j.actbio.2020.08.018.

11. Wang, J.L.; Xu, J.K.; Hopkins, C.; Chow, D.H.K.; Qin, L. Biodegradable Magnesium-Based Implants in Orthopedics-A General Review and Perspectives. Advanced science (Weinheim, Baden-Wurttemberg, Germany) 2020, 7, 1902443. doi:10.1002/advs.201902443.

12. Wen, P.; Voshage, M.; Jauer, L.; Chen, Y.; Qin, Y.; Poprawe, R.; Schleifenbaum, J.H. Laser additive manufacturing of Zn metal parts for biodegradable applications: Processing, formation quality and mechanical properties. Materials $\mathcal{E}$ Design 2018, 155, 36-45. doi:10.1016/j.matdes.2018.05.057.

13. Qin, Y.; Wen, P.; Guo, H.; Xia, D.; Zheng, Y.; Jauer, L.; Poprawe, R.; Voshage, M.; Schleifenbaum, J.H. Additive manufacturing of biodegradable metals: Current research status and future perspectives. Acta biomaterialia 2019, 98, 3-22. doi:10.1016/j.actbio.2019.04.046.

14. Li, Y.; Jahr, H.; Lietaert, K.; Pavanram, P.; Yilmaz, A.; Fockaert, L.I.; Leeflang, M.A.; Pouran, B.; Gonzalez-Garcia, Y.; Weinans, H.; Mol, J.M.C.; Zhou, J.; Zadpoor, A.A. Additively manufactured biodegradable porous iron. Acta biomaterialia 2018, 77, 380-393. doi:10.1016/j.actbio.2018.07.011.

15. Li, Y.; Jahr, H.; Pavanram, P.; Bobbert, F.S.L.; Paggi, U.; Zhang, X.Y.; Pouran, B.; Leeflang, M.A.; Weinans, H.; Zhou, J.; Zadpoor, A.A. Additively manufactured functionally graded biodegradable porous iron. Acta biomaterialia 2019, 96, 646-661. doi:10.1016/j.actbio.2019.07.013.

16. Song, B.; Dong, S.; Deng, S.; Liao, H.; Coddet, C. Microstructure and tensile properties of iron parts fabricated by selective laser melting. Optics E Laser Technology 2014, 56, 451-460. doi:10.1016/j.optlastec.2013.09.017.

17. Song, B.; Dong, S.; Liu, Q.; Liao, H.; Coddet, C. Vacuum heat treatment of iron parts produced by selective laser melting: Microstructure, residual stress and tensile behavior. Materials $\mathcal{E}$ Design (1980-2015) 2014, 54,727-733. doi:10.1016/j.matdes.2013.08.085.

18. Montani, M.; Demir, A.; Mostaed, E.; Vedani, M.; Previtali, B. Processability of pure Zn and pure Fe by SLM for biodegradable metallic implant manufacturing. Rapid Prototyping Journal 2017. doi:10.1108/RPJ-08-2015-0100.

19. Yang, Y.; Yuan, F.; Gao, C.; Feng, P.; Xue, L.; He, S.; Shuai, C. A combined strategy to enhance the properties of Zn by laser rapid solidification and laser alloying. Journal of the Mechanical Behavior of Biomedical Materials 2018, 82, 51-60. doi:10.1016/j.jmbbm.2018.03.018.

20. Zhou, Y.; Wu, P.; Yang, Y.; Gao, D.; Feng, P.; Gao, C.; Wu, H.; Liu, Y.; Bian, H.; Shuai, C. The microstructure, mechanical properties and degradation behavior of laser-melted Mg Sn alloys. Journal of Alloys and Compounds 2016, 687, 109-114. doi:10.1016/j.jallcom.2016.06.068.

21. Ng, C.C.; Savalani, M.M.; Lau, M.L.; Man, H.C. Fabrication of magnesium using selective laser melting technique. Rapid Prototyping Journal 2011. doi:10.1108/13552541111184206.

22. Ng, C.C.; Savalani, M.M.; Lau, M.L.; Man, H.C. Microstructure and mechanical properties of selective laser melted magnesium. Applied Surface Science 2011, 257, 7447-7454. doi:10.1016/j.apsusc.2011.03.004.

23. Wei, K.; Zeng, X.; Wang, Z.; Deng, J.; Liu, M.; Huang, G.; Yuan, X. Selective laser melting of Mg-Zn binary alloys: Effects of $\mathrm{Zn}$ content on densification behavior, microstructure, and mechanical property. Materials Science and Engineering: A 2019, 756, 226-236. doi:10.1016/j.msea.2019.04.067.

24. Kubásek, J.; Dvorský, D.; Čapek, J.; Pinc, J.; Vojtěch, D. Zn-Mg Biodegradable Composite: Novel Material with Tailored Mechanical and Corrosion Properties. Materials (Basel, Switzerland) 2019, 12. doi:10.3390/ma12233930. 
25. Frank, W.; Lucas, J.; Wolfgang, M.; Zienab, K.; Kristin, S.; Tanja, S. Open-porous biodegradable magnesium scaffolds produced by selective laser melting for individualized bone replacement. Frontiers in Bioengineering and Biotechnology $2016,4$. doi:10.3389/conf.fbioe.2016.01.00708.

26. Kopp, A.; Derra, T.; Müther, M.; Jauer, L.; Schleifenbaum, J.H.; Voshage, M.; Jung, O.; Smeets, R.; Kröger, N. Influence of design and postprocessing parameters on the degradation behavior and mechanical properties of additively manufactured magnesium scaffolds. Acta biomaterialia 2019, 98, 23-35. doi:10.1016/j.actbio.2019.04.012.

27. Cockerill, I.; Su, Y.; Sinha, S.; Qin, Y.X.; Zheng, Y.; Young, M.L.; Zhu, D. Porous zinc scaffolds for bone tissue engineering applications: A novel additive manufacturing and casting approach. Materials science $\mathcal{E}$ engineering. C, Materials for biological applications 2020, 110, 110738. doi:10.1016/j.msec.2020.110738.

28. Li, Y.; Pavanram, P.; Zhou, J.; Lietaert, K.; Taheri, P.; Li, W.; San, H.; Leeflang, M.A.; Mol, J.M.C.; Jahr, H.; Zadpoor, A.A. Additively manufactured biodegradable porous zinc. Acta biomaterialia 2020, 101, 609-623. doi:10.1016/j.actbio.2019.10.034.

29. Han, H.S.; Loffredo, S.; Jun, I.; Edwards, J.; Kim, Y.C.; Seok, H.K.; Witte, F.; Mantovani, D.; Glyn-Jones, S. Current status and outlook on the clinical translation of biodegradable metals. Materials Today 2019, 23, 57-71. doi:10.1016/j.mattod.2018.05.018.

30. Zheng, Y.F.; Gu, X.N.; Witte, F. Biodegradable metals. Materials Science and Engineering: R: Reports 2014, 77, 1-34. doi:10.1016/j.mser.2014.01.001.

31. Li, P. Absorbable Zinc-based alloy for craniomaxillofacial osteosynthesis implants. Faculty of Medicine; Eberhard Karls University Tübingen 2020.

32. Kannan, M.B.; Moore, C.; Saptarshi, S.; Somasundaram, S.; Rahuma, M.; Lopata, A.L. Biocompatibility and biodegradation studies of a commercial zinc alloy for temporary mini-implant applications. Scientific reports 2017, 7, 15605. doi:10.1038/s41598017-15873-w.

33. Meiners, W. Direktes selektives Laser-Sintern einkomponentiger metallischer Werkstoffe. PhD thesis, Zugl.: Aachen, Techn. Hochsch, Zugl. Aachen, 1999.

34. Ulutan, S.; Gilbert, M. Mechanical properties of HDPE/magnesium hydroxide composites. Journal of Materials Science 2000, 35, 2115-2120. doi:10.1023/A:1004746003076.

35. Ulian, G.; Valdrè, G. Anisotropy and directional elastic behavior data obtained from the second-order elastic constants of portlandite $\mathrm{Ca}(\mathrm{OH}) 2$ and brucite $\mathrm{Mg}(\mathrm{OH}) 2$. Data in brief 2018, 21, 1375-1380. doi:10.1016/j.dib.2018.10.139.

36. Yao, C.; Wu, Z.; Zou, F.; Sun, W. Thermodynamic and Elastic Properties of Magnesite at Mantle Conditions: First-Principles Calculations. Geochemistry, Geophysics, Geosystems 2018, 19, 2719-2731. doi:10.1029/2017GC007396. 